\title{
ANALISIS TINGKAT KEPUASAN PELANGGAN EMERY BARBERSHOP DENGAN MENGGUNAKAN METODE CUSTOMER SATISFACTION INDEX DAN IMPORTANCE PERFORMANCE ANALYSIS
}

\author{
RANDA PRATAMA SURIANTO, RIRI LESTARI, YUDIANTRI ASDI \\ Program Studi Matematika, \\ Fakultas Matematika dan Ilmu Pengetahuan Alam, Universitas Andalas, \\ Kampus UNAND Limau Manis Padang, Indonesia, \\ email : randapratama8819@gmail.com
}

\begin{abstract}
Abstrak. Kualitas pelayanan adalah tingkat baik atau buruknya suatu produk/jasa. Kualitas pelayanan yang baik merupakan salah satu titik ukur dari perkembangan suatu perusahaan atau instansi. Hal tersebut dapat dinilai dari kepuasan pelanggan terhadap pelayanan yang diberikan perusahaan tersebut. Penilitian ini mengamati kualitas pelayanan jasa pada Emery Barbershop yang bertujuan untuk mengetahui persepsi pelanggan terhadap indikator-indikator dalam dimensi kualitas jasa dengan menggunakan metode Costumer Satisfaction Index (CSI) dan metode Importance Performance Analysis (IPA). Dimensi kualitas pelayanan ada lima, yaitu tangible, reliability, responsiveness, assurance, dan emphaty. Dari hasil perhitungan Costumer Satisfaction Index (CSI) diperoleh $83,41 \%$. Hal ini berarti pelanggan telah merasa puas terhadap pelayanan yang diberikan oleh Emery Barbershop, sedangkan dengan metode Importance Performance Analysis (IPA), dengan analisis kuadran terdapat 3 indikator yang menjadi prioritas utama untuk ditingkatkan kinerjanya yaitu kebersihan toilet, keadaan tempat ibadah, dan kepedulian karyawan terhadap keluhan pelanggan.

Kata Kunci: Customer Satisfaction Index (CSI), Importance Performance Analysis (IPA), Kualitas pelayanan, Kepuasan pelanggan
\end{abstract}

\section{Pendahuluan}

Tampil rapi dan menarik tidak lagi hanya kebutuhan wanita. Kini, para pria juga ingin selalu tampil rapi dan menawan dalam setiap kegiatan. Banyak hal yang pria perhatikan terkait penampilannya, salah satunya adalah gaya rambut. Ini membuat kebutuhan akan jasa pangkas rambut terus meningkat. Alhasil usaha pangkas rambut pun semakin menjamur. Pangkas rambut merupakan salah satu jenis usaha yang masuk kedalam kategori usaha yang bergerak dalam bidang jasa, yang mana didalamnya menyediakan jasa potong rambut untuk para pelanggan.

Namun pada era sekarang ini pangkas rambut tidak lagi menjadi pilihan satusatunya bagi pria. Banyak pria yang beralih dari jasa pangkas rambut ke barbershop. Dalam hal nama pangkas rambut dan barbershop sejatinya sama, namun dalam hal konsep sangatlah berbeda. Pangkas rambut biasa hanya menyediakan jasa potong rambut, dan juga memiliki ruangan yang biasa-biasa saja. Sedangkan barbershop memiliki banyak kelebihan dari pada jasa pangkas rambut, yaitu seperti layanan 
pijat kepala, rileksasi dengan handuk panas dan facial, tempat penjualan produk perawatan rambut, dan juga memiliki ruangan yang nyaman dengan full $A C$.

Emery Barbershop merupakan salah satu barbershop yang ada di Kota Padang. Emery Barbershop selalu melakukan banyak cara untuk mendapatkan perhatian dari masyarakat maupun untuk mempertahankan pelanggannya. Salah satu cara yang dilakukan oleh Emery Barbershop dalam usaha mempertahankan loyalitas pelanggannya adalah dengan tetap membina hubungan yang baik dengan setiap pelanggan.

Akan tetapi kritik dan saran selalu datang dalam perjalanan Emery Barbershop hingga saat ini. Oleh sebab itu, penelitian ini bertujuan untuk menganalisa tingkat kepuasan pelanggan Emery Barbershop dan merumuskan indikator pelayanan yang akan diperbaiki dan dipertahankan. Peneliti terdorong untuk meneliti apakah strategi yang dilakukan oleh Emery Barbershop dapat memuaskan pelanggannya dengan memberikan pelayanan yang berkualitas. Salah satu metode yang dapat digunakan untuk menganalisa tingkat kepuasan pelanggan adalah metode Costumer Satisfaction Index. Sedangkan untuk merumuskan indikator pelayanan yang akan diperbaiki dan dipertahankan dapat menggunakan analisis kuadran dengan metode Importance Performance Analysis.

\section{Kualitas Pelayanan Jasa dan Kepuasan Pelanggan}

Kualitas jasa berpusat pada upaya pemenuhan dan keinginan pelanggan serta ketepatan penyampainnya untuk mengimbangi harapan pelanggan. [3] Terdapat lima dimensi kualitas jasa, yaitu:

(1) Tangibles (bukti langsung), meliputi fasilitas fisik, perlengkapan, penampilan pegawai, dan sarana komunikasi.

(2) Reliability (keandalan), yakni kemampuan memberikan pelayanan yang dijanjikan dengan secara tepat, akurat, dan memuaskan.

(3) Responsiveness (daya tanggap), yakni keinginan dan kesediaan para karyawan untuk membantu para pelanggan dan memberikan layanan dengan cepat tanggap.

(4) Assurance (jaminan), mencakup pengetahuan, kemampuan, kesopanan, sifat dapat dipercaya yang dimiliki para karyawan, bebas dari bahaya dan risiko, dan keragu-raguan.

(5) Emphaty (empati), meliputi kemudahan dalam menjalin hubungan, komunikasi yang efektif, perhatian personal, dan pemahaman atas kebutuhan individual para pelanggan.

Kepuasan adalah perasaan senang atau kecewa seseorang yang dialami setelah membandingkan antara persepsi kinerja atau hasil suatu produk/jasa dengan harapannya. Faktor utama yang perlu diperhatikan dalam kaitannya dengan kepuasan pelanggan antara lain:

(1) Kualitas Produk.

(2) Kualitas Pelayanan.

(3) Emosional. 
(4) Harga.

Pengujian statistik yang digunakan pada penelitian ini adalah validitas dan reliabilitas. Uji validitas bertujuan untuk melihat kevaliditan suatu data yang dilakukan dengan menghitung korelasi product moment yang dilanjutkan dengan melakukan uji $r$. Uji reliabilitas bertujuan untuk melihat kekonsistenan suatu data yang dilakukan dengan menghitung koefisien reliabilitas (Alpha Cronbach) menggunakan persamaan:

$$
C_{x \alpha}=\left(\frac{k}{k-1}\right)\left(1-\frac{\sum_{j=1}^{k} \sigma_{x j}^{2}}{\sigma_{x}^{2}}\right)
$$

Keterangan :

$$
\begin{aligned}
\sigma_{x}^{2} & =\text { variansi skor total } \\
\sigma_{x j}^{2} & =\text { variansi skor setiap pertanyaan }
\end{aligned}
$$

\section{Customer Satisfaction Index (CSI)}

Customer Satisfaction Index (CSI) digunakan untuk mengetahui tingkat kepuasan pelanggan secara menyeluruh dengan melihat tingkat kepentingan dari indikatorindikator kualitas pelayanan produk/jasa. [1] Adapun langkah-langkah untuk menentukan CSI, yaitu:

(1) Mean Satisfaction Score (MSS)

$$
M S S_{j}=\frac{\sum_{i=1}^{n} x_{i j}}{n}
$$

(2) Mean Importance Score (MIS)

$$
M I S_{j}=\frac{\sum_{i=1}^{n} y_{i j}}{n}
$$

(3) Weighted Score (WS)

$$
W S_{j}=W F_{j} \times M S S_{j}
$$

(4) Customer Satisfaction Index (CSI)

$$
C S I=\frac{\sum_{j=1}^{k} W S_{j}}{H S \times \sum_{j=1}^{k} M I S_{j}} \times 100 \%
$$

dengan HS: (Highest Scale) = skala maksimum yang digunakan

\section{Importance Performance Analysis (IPA)}

Importance Performance Analysis (IPA) yaitu analisis kuadran yang digunakan untuk menilai respon pelanggan terhadap indikator yang diplotkan berdasarkan rata-rata kinerja $\left(\bar{x}_{j}\right)$ pada sumbu $x$ dan rata-rata kepentingan $\left(\bar{y}_{j}\right)$ pada sumbu $y$ dalam diagram kartesius yang dibagi kedalam empat kuadran. Selanjutnya, menentukan nilai $\overline{\bar{x}}$ dan $\overline{\bar{y}}$ sebagai pembatas untuk masing-masing kuadran. [2] Adapun setiap hasil yang menempati salah satu kuadran dalam diagram kartesius, yaitu : 
(1) Kuadran I (Prioritas Utama)

Memuat faktor-faktor yang dianggap penting oleh pelanggan, tetapi pada kenyataannya belum sesuai dengan harapan pelanggan (kinerjanya masih rendah).

(2) Kuadran II (Pertahankan Kinerja)

Memuat faktor-faktor yang dianggap penting oleh pelanggan dan tingkat kepuasannya relatif lebih tinggi (kinerjanya sudah tinggi)

(3) Kuadran III (Prioritas Rendah)

Memuat faktor-faktor yang dianggap kurang penting oleh pelanggan, tetapi pada kenyatannya kinerjanya masih rendah.

(4) Kuadran IV (Berlebihan)

Memuat faktror-faktor yang dianggap kurang penting dan dirasakan terlalu berlebihanoleh pelanggan (kinerjanya relatif tinggi).

\section{Customer Satisfaction Index (CSI) dan Importance Performance Analysis (IPA) pada Emery Barbershop}

Dalam penelitian ini peneliti menggunakan data primer yang diperoleh melalui kuisioner yang dibagikan kepada pelanggan Emery Barbershop yang telah menggunakan jasa. Pengambilan sampel dilakukan dengan cara Simple Random Sampling yang artinya dalam memilih sampel, semua anggota populasi diberikan kesempatan yang sama untuk ditetapkan sebagai anggota sampel.

Dalam menentukan nilai CSI diperlukan nilai Weight Score (WS) yaitu merupakan hasil perkalian dari nilai MIS dan MSS.

Tabel 1. Perhitungan MIS, MSS dan WS

\begin{tabular}{|c|c|c|c|c|}
\hline No & Indikator & MSS & MIS & WS \\
\hline 1 & Kenyamanan ruang tunggu & 4,2439 & 4,2927 & 18,2177 \\
\hline 2 & Kebersihan ruang potong rambut & 3,9878 & 4,1951 & 16,7293 \\
\hline 3 & Kebersihan toilet & 3,1829 & 4,2561 & 13,5468 \\
\hline 4 & Tempat parkir luas & 2,9756 & 4,1585 & 12,3742 \\
\hline 5 & Kelengkapan peralatan kerja & 4,0488 & 4,2561 & 17,2320 \\
\hline 6 & Kerapian penampilan karyawan & 3,5000 & 4,0976 & 14,3415 \\
\hline 7 & Keadaan tempat ibadah & 3,1951 & 4,2805 & 13,6767 \\
\hline 8 & Keahlian karyawan menggunakan perangkat kerja & 3,9634 & 4,1951 & 16,6270 \\
\hline 9 & Kecepatan karyawan melayani pelanggan & 3,2317 & 3,9756 & 12,8480 \\
\hline 10 & Kesigapan karyawan ketika pelanggan datang & 2,9756 & 4,1341 & 12,3016 \\
\hline 11 & Kesigapan karyawan menangani permintaan pelanggan & 3,6585 & 4,0366 & 14,7680 \\
\hline 12 & Kemampuan karyawan memberikan saran model rambut & 3,8659 & 4,0488 & 15,6520 \\
\hline 13 & Tata krama karyawan menangani pelanggan & 4,2317 & 4,2805 & 18,1138 \\
\hline 14 & Hasil model rambut sesuai permintaan pelanggan & 3,8415 & 4,2073 & 16,1623 \\
\hline 15 & Keamanan tempat parkir & 4,2195 & 4,2561 & 17,9587 \\
\hline 16 & Pelayanan berurutan sesuai antrian & 4,0854 & 4,2561 & 17,3877 \\
\hline 17 & Sikap semangat karyawan saat bekerja & 3,8293 & 4,0244 & 15,4105 \\
\hline 18 & Sikap bersahabat karyawan kepada semua pelanggan & 3,9390 & 4,0366 & 15,9002 \\
\hline 19 & Kepedulian karyawan terhadap keluhan pelanggan & 3,5854 & 4,1951 & 15,0410 \\
\hline
\end{tabular}

Berdasarkan hasil perhitungan pada Tabel 1. diatas, dapat dihitung nilai Customer Satisfaction Index dengan menggunakan persamaan 3.4, dimana $\mathrm{k}=19$.

$$
C S I=\frac{\sum_{j=1}^{p} W S_{j}}{H S \times \sum_{j=1}^{k} M I S} \times 100 \%=83,41 \%
$$

Nilai CSI yang diperoleh adalah $83,41 \%$ yang menunjukkan nilai tersebut berada pada interval $0,81-1,00$. Hal ini menyatakan bahwa secara umum pelanggan merasa sangat puas terhadap pelayanan yang diberikan Emery Barbershop. 
Selanjutnya akan dilihat perbandingan antara rata-rata skor kinerja yang disimbolkan dengan $x_{j}$ dan rata-rata skor kepentingan yang disimbolkan dengan $y_{j}$ dengan menggunakan metode Importance Performance Analysis (IPA) yang kemudian digambarkan dalam diagram kartesius. Hal ini bertujuan untuk mengetahui kinerja pelayanan dan kepentingan pelanggan terhadap indikator dalam peningkatan dan pertahankan kualitas pelayanan Emery Barbershop.

Tabel 2. Koordinat (Kinerja $\left(\overline{x_{j}}\right) ;$ Kepentingan $\left(\overline{y_{j}}\right)$ )

\begin{tabular}{|c|c|c|c|}
\hline No & Indikator & \multicolumn{2}{c|}{ Titik Koordinat } \\
\cline { 3 - 4 } & & $\left(\overline{x_{j}}\right)$ & $\left(\overline{y_{j}}\right)$ \\
\hline \hline 1 & Kenyamanan ruang tunggu & 4,2439 & 4,2927 \\
\hline 2 & Kebersihan ruang potong rambut & 3,9878 & 4,1951 \\
\hline 3 & Kebersihan toilet & 3,1829 & 4,2561 \\
\hline 4 & Tempat parkir luas & 2,9756 & 4,1585 \\
\hline 5 & Kelengkapan peralatan kerja & 4,0488 & 4,2561 \\
\hline 6 & Kerapian penampilan karyawan & 3,5000 & 4,0976 \\
\hline 7 & Keadaan tempat ibadah & 3,1951 & 4,2805 \\
\hline 8 & Keahlian karyawan menggunakan perangkat kerja & 3,9634 & 4,1951 \\
\hline 9 & Kecepatan karyawan melayani pelanggan & 3,2317 & 3,9756 \\
\hline 10 & Kesigapan karyawan ketika pelanggan datang & 2,9756 & 4,1341 \\
\hline 11 & Kesigapan karyawan menangani permintaan pelanggan & 3,6585 & 4,0366 \\
\hline 12 & Kemampuan karyawan memberikan saran model rambut & 3,8659 & 4,0488 \\
\hline 13 & Tata krama karyawan menangani pelanggan & 4,2317 & 4,2805 \\
\hline 14 & Hasil model rambut sesuai permintaan pelanggan & 3,8415 & 4,2073 \\
\hline 15 & Keamanan tempat parkir & 4,2195 & 4,2561 \\
\hline 16 & Pelayanan berurutan sesuai antrian & 4,0854 & 4,2561 \\
\hline 17 & Sikap semangat karyawan saat bekerja & 3,8293 & 4,0244 \\
\hline 18 & Sikap bersahabat karyawan kepada semua pelanggan & 3,9390 & 4,0366 \\
\hline 19 & Kepedulian karyawan terhadap keluhan pelanggan & 3,5854 & 4,1951 \\
\hline
\end{tabular}

Selanjutnya akan dihitung nilai $\overline{\bar{x}}$ dan $\overline{\bar{y}}$ dengan $k=19$, yaitu:

$$
\overline{\bar{x}}=\frac{\sum_{j=1}^{19} \bar{x}_{j}}{19}=3,7137 \text {, dan } \overline{\bar{y}}=\frac{\sum_{j=1}^{19} \bar{y}_{j}}{19}=4,1675 \text {. }
$$

Nilai $\overline{\bar{x}}$ akan memotong diagram secara tegak lurus pada sumbu horizontal di titik $(3,7137 ; 0)$ dan nilai $\overline{\bar{y}}$ memotong diagram secara tegak lurus pada sumbu vertikal di titik $(0 ; 4,1675)$. Kedua garis tersebut akan membentuk empat kuadran. Selanjutnya titik-titik yang menjadi koordinat untuk masing-masing indikator, diplot ke dalam diagram kartesius dan diberi angka (nomor) pada setiap titik koordinat. Angka tersebut bertujuan untuk menandakan letak masing-masing indikator sesuai urutan yang telah dibuat sebelumnya.

Gambar 1. menampilkan peta sebaran masing-masing indikator dalam diagram kartesius yang dikelompokkan dengan warna yang berbeda untuk setiap dimensi. Titik warna merah melambangkan indikator yang termasuk dimensi tangible, warna biru melambangkan indikator yang termasuk dimensi reliability, warna hijau melambangkan indikator yang termasuk dimensi responsiveness, warna hitam melambangkan indikator yang termasuk dimensi assurance dan warna kuning melambangkan indikator yang termasuk dimensi empathy.

\section{Kuadran I (Prioritas Utama).}

Wilayah yang memuat indikator-indikator dengan tingkat kepentingan yang relatif tinggi tetapi kenyataannya belum sesuai dengan harapan pelanggan (kinerja yang masih rendah). Indikator yang termasuk kedalam kuadran ini harus dilakukan perbaikan secara terus menerus sehingga kinerjanya meningkat. Indikator-indikator 


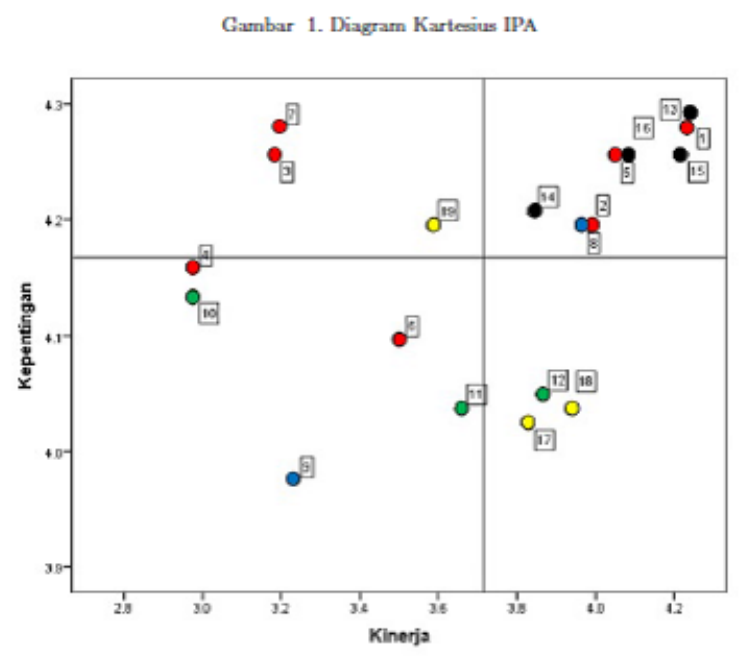

yang termasuk kedalam kuadran ini adalah indikator berdimensi tangible yaitu kebersihan toilet (3) dan keadaan tempat ibadah (7). Indikator berdimensi emphaty yaitu kepedulian karyawan terhadap keluhan pelanggan (19).

2. Kuadran II (Pertahankan Kinerja) Wilayah yang memuat indikatorindikator yang memiliki tingkat kepentingan dan tingkat kinerja yang relatif tinggi. Indikator yang termasuk kedalam kuadran ini tetap dipertahankan karena semua indikator ini menjadikan pelayanan yang diberikan unggul dimata pelanggan. Indikator-indikator yang termasuk kedalam kuadran ini adalah indikator berdimensi tangible yaitu kenyamanan ruang tunggu (1), kebersihan ruang potong rambut (2), kelengkapan peralatan kerja (5), keahlian karyawan menggunakan perangkat kerja (8). Indikator berdimensi assurance yaitu tata krama pelanggan menangani pelanggan (13), model rambut yang dihasilkan sesuai permintaan pelanggan (14), keamanan tempat parkir (15), dan pelayanan berurutan sesuai antrian (16).

3. Kuadran III (Prioritas Rendah) Wilayah yang memuat indikator-indikator dengan tingkat kepentingan yang relatif rendah dan kinerjanya juga relatif rendah. Peningkatan indikator yang termasuk kedalam kuadran ini dapat dipertimbangkan kembali karena berpengaruh juga terhadap kepuasan pelanggan. Indikator-indikator yang termasuk kedalam kuadran ini adalah indikator berdimensi tangible yaitu tempat parkir luas (4), kerapian penampilan karyawan (6), dan kecepatan karyawan melayani pelanggan (9). Indikator berdimensi reliability yaitu kesigapan karyawan saat pelanggan datang (10) dan kesigapan karyawan menangani permintaan pelanggan (11).

4. Kuadran IV (Berlebihan) Wilayah yang memuat indikator-indikator dengan tingkat kepentingan yang relatif rendah dan dirasakan oleh pelanggan terlalu berlebihan (kinerja yang relatif tinggi. Indikator-indikator yang termasuk ke dalam kuadran ini adalah indikator berdimensi responsiveness yaitu kemampuan karyawan memberikan saran model rambut (12). Indikator berdimensi emphaty yaitu sikap 
semangat karyawan saat bekerja (17) dan sikap bersahabat karyawan kepada semua pelanggan (18).

\section{Kesimpulan}

Dari hasil penelitian yang dilakukan dapat disimpulkan bahwa secara umum pelanggan telah merasa puas dengan pelayanan yang diberikan oleh pihak Emery Barbershop. Hal ini terlihat dari nilai Customer Satisfaction Index sebesar 83,41\%. Namun itu masih belum maksimal sehingga perlu ditingkatkan lagi agar pelanggan lebih merasa puas terhadap kualitas pelayanan yang diberikan oleh Emery Barbershop. Berdasarkan hasil pengolahan yang dilakukan dengan Importance Performance Analysis (IPA), dapat diketahui indikator-indikator yang harus dibenahi yaitu kebersihan toilet, keadaan tempat ibadah, dan kepedulian karyawan terhadap keluhan pelanggan.

\section{Ucapan Terima Kasih}

Penulis mengucapkan terima kasih kepada Bapak Dodi Devianto, Ibu Hazmira Yozza dan Bapak Budi Rudianto yang telah memberikan masukan dan saran sehingga paper ini dapat diselesaikan dengan baik.

\section{Daftar Pustaka}

[1] Maiyanti, S.I., dkk. 2009. Aplied Costumer Satisfaction Index (CSI) and Importance Performance Analysis (IPA) to know Student Satisfaction Level of Sriwijaya University Library Services. Jurnal Matematika FMIPA, Universitas Sriwijaya. Palembang

[2] Nazir, M. 2005.Metode Penelitian. Ghalia Indonesia. Bogor.

[3] Parasuraman, V.A. Zeithaml dan L.L, Berry. 1998. A Multiple Item Scale for Meansuring Consumer Perseption of Service Quality. Jurnal of Retailling. 